\title{
Extracting past atmospheric warming and urban heating effects from borehole temperature profiles
}

Peter Bayer ${ }^{*}$, Jaime A. Rivera ${ }^{1}$, Daniel Schweizer ${ }^{2}$, Ulrich Schärli ${ }^{3}$, Philipp Blum ${ }^{4}$, Ladislaus Rybach $^{1}$

${ }^{1}$ Department of Earth Sciences, ETH Zurich, Zurich, Switzerland

${ }^{2}$ Department of Civil, Environmental and Geomatic Engineering, ETH Zurich, Zurich, Switzerland

${ }^{3}$ Dr. Ulrich Schärli Geologie+Geophysik, Zurich, Switzerland

${ }^{4}$ Institute for Applied Geosciences, Karlsruhe Institute of Technology (KIT), Karlsruhe, Germany

*Corresponding author: P. Bayer, Department of Earth Sciences, ETH Zurich, Sonneggstr. 5, 8092 Zurich, Switzerland (mail@ bayerpeter.com) 


\begin{abstract}
Borehole temperature logs in urban areas often show deviation from the regional geothermal gradient that increases towards the land surface in the top $\sim 100$ meters. This deviation is the sum of two effects: atmospheric global warming and urban heating. To invert the temperature profiles (T-logs), a novel analytical model is presented to distinguish effects of global warming and of urban structures on the ground thermal regime. The inversion is demonstrated on four characteristic T-logs measured in the city and suburbs of Zurich, Switzerland. The logging was performed in borehole heat exchanger U-tubes by an innovative, wireless measuring technique. Detailed information on past climatic and land use changes enabled the focus on two main urban heat sources, buildings and asphalt. For three of the locations, the Tlogs could be reproduced with a plausible heating of the asphalt by $3-3.5{ }^{\circ} \mathrm{C}$, and an average temperature of $15-16{ }^{\circ} \mathrm{C}$ below the basement of buildings. However, the other location within the highly urbanized area, is influenced by additional heat sources. In most of the cases, the increased subsurface temperatures and the associated stored additional geothermal energy, mainly originate from urban structures, while climate change is secondary.
\end{abstract}

Keywords land use change, borehole climatology, Bayesian inversion, analytical model, conduction 


\section{Introduction}

Vertical temperature profiles (T-logs) measured in boreholes can be utilized as long-term recordings of past atmospheric temperature variations and recent global warming (Harris and Chapman, 1997; Huang et al., 2000; Lachenbruch and Marshall, 1986; Pollack and Huang, 2000). This is due to the coupling between ground surface temperature (GST) and surface air temperature (SAT), as well as slow heat transport in geological formations. In borehole climatology, different concepts are available for relating spatially variable temperature in the ground to the temporal variations above the ground. Most commonly, one-dimensional vertical conductive heat flux is assumed as the governing process, and by inversion with an analytical half space conduction model, climatic temperature trends for the last centuries and beyond are derived (Barkaoui et al., 2013; Bodri and Cermak, 2011; Davis et al., 2010; Hartmann and Rath, 2005; Lewis and Wang, 1992; Mareschal and Beltrami, 1992; Smerdon et al., 2003). For simulating the combined effect of vertical groundwater flow and conduction, analytical advection-conduction models are applied (Kurylyk and MacQuarrie, 2014; Taniguchi et al., 1999; Yamano et al., 2009). Alternatively, in order to account for spatial parameter heterogeneity, local groundwater flow, terrain or topographical effects, more flexible and versatile numerical models are employed (Hopcroft et al., 2009; Kohl, 1999; Kooi, 2008; Vogt et al., 2014).

When T-logs are used for past climate inversion, focus is set on atmospheric forcing. The neglect of specific heat sources or thermal transport processes may result in misinterpretation. It is well known that changes in land use and coverage perturb the thermal regime in the ground. For example, increased temperatures are induced from changes of annual snow cover, deforestation, and urban infrastructures (Bense and Beltrami, 2007; Dutra et al., 2011; Kataoka et al., 2009; Lewis and Wang, 1992; Mann and Schmidt, 2003; Nitoiu and Beltrami, 2005). However, even if perturbed T-logs are too noisy for past climate reconstruction, this 
apparent noise carries precious information about direct anthropogenic effects. When GST trends are known, e.g. based on SAT measurements or from close-by non-perturbed profiles, it is possible for example to examine the evolution of urbanization in T-logs (Ferguson and Woodbury, 2004; Taniguchi et al., 2009; Yamano et al., 2009; Zhu et al., 2014; Zhu et al., 2010). For example, in several Asian cities such as Osaka, Bangkok, Taipei, Jakarta, Seoul, and Tokyo, Taniguchi and co-workers (Huang et al., 2009; Taniguchi et al., 1999; Taniguchi et al., 2007; Taniguchi et al., 2005) inspected the footprint from the atmospheric urban heat island (UHI) in the subsurface.

Despite the fact that large-scale spatial trends in cities have been identified and regional heat fluxes have been modelled, the main focus so far has been on average conditions and features that are reproduced in repeated measurements or at different locations. Much less effort has been dedicated to inspecting local urbanization effects. For instance, Reiter (2006) and Reiter (2007) measured T-logs in $120 \mathrm{~m}$ deep boreholes in the Albuquerque basin, and found that encroaching urbanization leads to increased temperatures. Westaway et al. (2015) examined the conditions in the vicinity of an industrial site and found substantially increased temperatures in the ground. Ferguson and Beltrami (2006) and Dědeček et al. (2012) presented numerical modelling studies for quantifying the theoretical impact of increased heat flux due to land use change and from buildings on T-logs. Dědeček et al. (2012) applied numerical models to two field cases in Prague (Czech Republic) and in Slovenia, where repeated measurements from around $150 \mathrm{~m}$ deep T-logs reveal substantial warming effects from the land surface. It was shown that forcing the numerical model with measured SAT temperatures yields insufficient vertical heat flux, and the observed rate of warming is around two times the modelled value for the borehole in Prague. By implementing different land use types (buildings, playground and asphalt areas) and assigning measured elevated values of specific temperatures, a fairly good agreement between simulated and measured logs can be 
achieved. Similar findings are obtained for the Slovenian borehole. However, due to the lack of detailed measurements, the temperatures characteristic for a sports hall $\left(17^{\circ} \mathrm{C}\right)$ and paved ground (offset of $3.5^{\circ} \mathrm{C}$ ) had to be manually calibrated.

As described, those approaches available for studying direct anthropogenic perturbation of Tlogs are based on mainly simplifying synthetic, or computationally demanding, case-specific, numerical models. Especially when long-term trends of land use changes are simulated, numerical methods demand long computing times for achieving a satisfactory time-resolution. This is prohibitive for automatic inversion techniques, which often require numerous iterations of model executions. Analytical models, which can be rapidly evaluated, are popular in borehole climatology but not considered for simulating spatially and temporally variable land use effects on T-logs. This gap is closed in our work. We therefore present an analytical model framework that can be utilized for T-log inversion with different land use types and conduction as dominating heat transport process. It is implemented into a Bayesian framework for reconstructing the past land use effects on T-logs measured in urban environments. Hence, our objective is to quantify the spatially and temporally variable contributions of different anthropogenic heat sources on T-logs. With this insight, we are able to distinguish effects of atmospheric global warming and of urban infrastructures on the ground thermal regime, which is not only crucial in the context of borehole climatology, but also for understanding the evolution of subsurface UHIs (Arola and Korkka-Niemi, 2014; Ferguson and Woodbury, 2004; Huang et al., 2009) and their geothermal potential (Zhu et al., 2010).

In the following, the analytical model and the inversion procedure is described first. Then, we report characteristic T-logs measured in the city and suburbs of Zurich, Switzerland. For the measurement locations, the land use variability in space and time is analysed and analytical 
models are calibrated. We finally derive characteristic temperature values for each land use type and reveal their sensitivities.

\section{Methodology}

\subsection{Analytical model}

Previous studies have highlighted the role of long-term changes in urban GST for explaining the thermal anomalies in the shallow urban subsurface (e.g. (Benz et al., 2015b; Dědeček et al., 2012) ). These changes are characterized by a strong spatiotemporal variability that challenges the performance of standard numerical heat transport solvers (Epting et al., 2013; Herbert et al., 2013). Recently, Rivera et al. (2015) proposed an analytical model for simulating borehole heat exchangers (BHEs) based on a superposition of Green's functions, which can simulate transient and non-uniform land-surface effects. This model is easily scalable in space and is appealing for use within standard T-log inversion procedures. Conceptually, the model is built for a semi-infinite homogeneous space bounded by a flat ground surface (top boundary). The latter consists of a rectangular area with a distinctive land use within the coordinates $\left[x_{a}, x_{b}\right]$ and $\left[y_{a}, y_{b}\right]$, which is embedded in an infinite plane (representing the background).

If the temperature of the rectangular area is $\emptyset_{l u}(t)$ and one of the infinite planes is zero, as well as the initial conditions, the temperature $T_{l u}$ at any point $\boldsymbol{x}=(x, y, z)$ and time $t$ reads (Rivera et al., 2015):

$$
T_{l u}(x, t)=\frac{1}{4 \sqrt{\pi}} \int_{\frac{z^{2}}{4 a t}}^{\infty} \frac{\emptyset_{l u}\left(t-\frac{z^{2}}{4 a u}\right)}{\sqrt{u}} \exp (-u)\left[\operatorname{erf}\left(\frac{y-y_{b}}{z} \sqrt{u}\right)-\right.
$$




$$
\left.\operatorname{erf}\left(\frac{y-y_{a}}{z} \sqrt{u}\right)\right]\left[\operatorname{erf}\left(\frac{x-x_{b}}{z} \sqrt{u}-\frac{v z}{4 a \sqrt{u}}\right)-\operatorname{erf}\left(\frac{x-x_{a}}{z} \sqrt{u}-\frac{v z}{4 a \sqrt{u}}\right)\right] d u
$$

where $v$ is the horizontal effective thermal velocity, which is assumed uniform and steady, and $a$ is the thermal diffusivity of the porous medium. It relates the bulk thermal conductivity, $\lambda$, the bulk specific heat capacity, $c$, and density, $\rho$, of the material by $a=\lambda /(c \rho)$.

If the initial thermal conditions are not zero but defined by a given surface temperature $T_{S}$ and an in-situ geothermal gradient $k$, the following expression is superposed to Eq. (1) (Carslaw and Jaeger, 1959):

$$
T_{o}(z, t)=T_{S} \operatorname{erf}\left(\frac{z}{\sqrt{4 a t}}\right)+k z
$$

Moreover, if the temperature of the infinite plane or background on top is not zero but $\emptyset_{\text {inf }}(t)$, we additionally superpose the following analytical expression (Carslaw and Jaeger, 1959):

$$
T_{\text {inf }}(z, t)=\frac{z}{2 \sqrt{\pi a}} \int_{0}^{t} \frac{\emptyset_{\text {inf }}(\tau)}{(t-\tau)^{3 / 2}} \exp \left[-\frac{z^{2}}{4 a(t-\tau)}\right] d \tau
$$

In this case, the function $\emptyset_{l u}(t)$ in Eq. (1) is replaced by $\emptyset_{l u}(t)-\emptyset_{\text {inf }}(t)$. Finally, the temperature at the point $\boldsymbol{x}$ and time $t$ reads:

$$
T(x, t)=T_{\text {inf }}(z, t)+T_{o}(z, t)+T_{l u}(\boldsymbol{x}, t)
$$

With Eqs. (1)-(4) it is possible to estimate complex land use settings via superposition as exemplified in the theoretical analysis by Rivera et al. (2015) on BHEs for geothermal energy use. In the present work, conditions without the operation of a BHE are considered. Also, potential heat loss from underground structures such as sewage channels or district heating systems is ignored (Benz et al., 2015a). 


\subsection{Inversion strategy}

For calibration to a measured T-log, a fundamental hurdle is that the number of different influential parameters to describe long-term spatial and temporal variations in an urban environment is huge, thus the inversion problem is not well delineated. For arriving at a reduced set of a few free parameters, we propose (i) predefining average thermal properties of the ground instead of including these in a calibration, (ii) grouping those parameters that are representative of different sources but the same processes and assigning averaged global values, and (iii) approximating trends in past GST temperatures based on polynomial regression of measured atmospheric data. Details and implications of these strategies are discussed in the following.

In the first step, the values of $T_{s}$ and $k$ in $T_{o}$ (Eq. (2)) have to be determined. For this, the linear trend defined by the ambient geothermal gradient, at sufficient depth of a T-log, is extended to the ground surface. This trend represents the expected and ideal site-specific conditions without distortions from the ground surface or from groundwater flow. By this, we also assume that thermal properties in the ground are homogeneous, or in other words, thermal conductivity can be approximated by one integral value. The value of the linear trend at the ground surface equals $T_{s}$ and the slope of this trend is $k$. The deviation from the initial linear trend is caused by distortion due to spatiotemporal variability in GST. The latter is split in two superimposed components: the prevailing GST influenced by climate conditions (background) and the effect of urbanization (land uses). These are described in the next section.

\subsection{Ground surface temperature components}

The background or outdoor urban GST, here GST $_{\text {out, }}$ is mainly controlled by the surface air temperature (SAT). Generally, both temperature fields are coupled, but to some extent they 
are detached from each other depending on site-specific conditions such as wind, evapotranspiration, land use type, and snow cover among others (Herb et al., 2008). Therefore, taking SAT as a surrogate of $\mathrm{GST}_{\text {out }}$ for solving the heat transport problem with prescribed temperature at the ground surface, is often not appropriate. At the regional scale, for instance, (Signorelli and Kohl, 2004) observed differences from $0.2{ }^{\circ} \mathrm{C}$ to $3.6^{\circ} \mathrm{C}$ between the annual mean of both temperature fields. For this, data from 29 measurement stations in Switzerland were considered. The data from (Signorelli and Kohl, 2004) also show that annual mean values of SAT and $\mathrm{GST}_{\text {out }}$ follow the same trend without appreciable phase shifting. This feature will be considered in this work for approximating the GST $_{\text {out }}$, provided a recorded SAT time series.

In urban Zurich, at Fluntern, the station SMA (MeteoSchweiz, 2015) has measured near surface air temperatures since before 1900. Figure 1 shows the annual mean SAT at this station for the period of 1880 to 2014. Earlier SAT measurements (not shown) do not indicate temperature trends and we deduce a mean SAT of $7.93{ }^{\circ} \mathrm{C}$ for the time before 1880 .

The continuous increase in SAT after 1900 is a common feature when we compare it with related studies in urban areas (e.g. (Yamano, 2011; Zhu et al., 2014)). Before circa 1900, the reconstructed GST history described in (Yamano et al., 2009) also shows a relatively stable GST period in the analysed cities of Bangkok and Taipei. This indicates that, similar to Zurich, effects from urbanization and global warming are not identifiable in very early time. In line with this, we assume that a quasi-thermal equilibrium in $\mathrm{GST}_{\text {out }}$ exists before 1880 for the initialisation of the model. This equilibrium in GST $_{\text {out }}$ is site-specific and identified using the parameters $T_{S}$ and $k$ in Eq. (2). Parameter $T_{S}$ is the initial $\mathrm{GST}_{\text {out, }}$ which is known from linear interpolation of the undisturbed T-log, and the temporal trend in $\mathrm{GST}_{\text {out }}$ is determined by the trend in the measured SAT. In the model, this means that we calculate the difference $\Delta T_{\mathrm{G}-\mathrm{S}}$ between initial GST $\left(T_{s}\right)$ and initial SAT $\left(7.93{ }^{\circ} \mathrm{C}\right)$, and use this increment to shift the 
values of SAT for approximating the $\mathrm{GST}_{\text {out }}$ trend during the long-term simulation (Figure 2). For convenience, the trend in this $\mathrm{GST}_{\text {out }}$ is fitted with a polynomial regression of SAT (Figure 1) and this expression is used as $\emptyset_{\text {inf }}(t)$ in Eq. (3). Thus, any seasonality in the $\mathrm{GST}_{\text {out }}$ signal is neglected, since only its long-term changes can be tracked from deeper Tlogs.

The obtained GST out $_{\text {trend, }} \emptyset_{\text {inf }}(t)$, is implemented in the model (Eq. (4)) and not calibrated. It is used as time-dependent background (or outdoor) temperature to describe areas other than sealed and covered ground. The latter are quantified by the other component in GST $\left(\emptyset_{l u}\right)$ accounting for changes in land use (Eq. 1). For our study cases, two different categories are identified: pavements (or asphalted areas) and buildings. For pavements, we follow the suggestions by Dědeček et al. (2012) and assume that these follow the same trend as the background $\mathrm{GST}_{\text {out }}\left(\emptyset_{\text {inf }}(t)\right)$ plus an unknown increment $\Delta T_{a}$ (Figure 2). For built-up areas, we hypothesize a constant annual mean ground surface temperature, $T_{B}$, regardless of the nature of building or transient patterns in heating/cooling demands (Figure 2).

The site-specific values of $\Delta T_{a}$ and $T_{B}$ could be determined via single model calibration, and thus minimizing the misfit between the model and T-log. However, given the ill-posedness of the inversion problem, we favour a Bayesian approach (Goto et al., 2009). For evaluating the likelihood distribution of the two unknown parameters, Metropolis-Hastings sampling (MHS) is performed (Hastings, 1970; Metropolis et al., 1953). This is a standard Markov-Chain Monte Carlo (MCMC) method that increases the efficiency of sampling by concentrating the search on domains with a high probability of the likelihood function. Even though such a MCMC method requires thousands of model evaluations, the overall calibration procedure is fast, given the efficient analytical solution of the transient 3-D heat transport problem. 


\section{Case study}

\subsection{Borehole temperature measurements}

Our approach ignores any advective heat transport component. Thus, groundwater wells, which often represent the most frequent and best accessible boreholes in a city, are not suitable. Instead, T-logs are taken in recently completed geothermal drill-holes in the region of Zurich before starting operation of a ground source heat pump. The boreholes were backfilled after drilling and equipped with double U-tubes. The tubes were filled with water and left standing for at least 7 days to reach thermal equilibration. For vertical temperature logging, a patented novel wireless probe, NIMO-T ("Non-wired Immersible Measuring Object for Temperature") was inserted in one of the water-filled U-tube limbs (Figure 3). The device, its specifications, and the measurement procedures are described in detail in (Rohner et al., 2005).

The NIMO-T probe (weight $100 \mathrm{~g}$, length $20 \mathrm{~cm}$, diameter $2 \mathrm{~cm}$ ) carries a temperature and pressure sensor, as well as a built-in miniature data logger. It sinks by its own weight at a rate of around 7 meters per minute, and it records a temperature and pressure (= measuring depth) value every $25 \mathrm{~cm}$. The relative temperature accuracy is $\pm 0.0015 \mathrm{~K}$, and for depth it is \pm 20 $\mathrm{cm}$ (time constant of temperature sensor is around $0.5 \mathrm{~s}$ ). After the probe has reached the Utube bottom, it is flushed back to the surface by pumping. The recorded data is then readout and processed in a computer (Schärli et al., 2007).

From several available measurements, we selected four locations, where groundwater effects are negligible. At these sites, hydrogeological maps do not show productive aquifers. During drilling no water inflow was observed and no advective distortions could be perceived in the obtained T-logs. The boreholes are located in the area of Zurich, as well as in the suburbs 
around the lake of Zurich. For the sake of simplicity, we name the boreholes according to their relative geographical positions: Southeast, South, East, and Central (Figure 4, Table 1).

In the Southeast, in the suburb of Meilen, a borehole of $280 \mathrm{~m}$ was logged in October 2005. This location is typical for old residential areas in the region of Zurich. In contrast, the South location on the western side of the Zurich Lake, represents a recently populated area with mainly industrial land use since 1962 . Here, the temperature profile goes to $200 \mathrm{~m}$ depth and was taken in September 2008. The two further and most recent measurements are from the city area of Zurich. The one in the East is located at the Köllikerstrasse, and the other in the Central at the Rämistrasse. Both reach a depth of more than $400 \mathrm{~m}$. The East location is characteristic for a residential area, with separate houses and green spaces. The Central location exhibits the highest building density, with a small fraction of green spaces.

The drilling profiles of the four sites are case-specific, but show similar sediments. The subsurface is built up mainly by consolidated fine sand of the Upper Freshwater Molasse (Tertiary). It is overlain by young Quaternary moraine deposits, of $53 \mathrm{~m}$ in the South, $26 \mathrm{~m}$ in the East and $15 \mathrm{~m}$ in the Central. In the Southeast, the Tertiary formation reaches to the ground surface. Previous works (Schärli et al., 2007; Stauffer et al., 2013) provide representative values for thermal conductivity, $\lambda=2.7 \mathrm{~W} / \mathrm{m} \mathrm{K}$, bulk density of $\rho=2700$ $\mathrm{kg} / \mathrm{m}^{3}$ and $c=700 \mathrm{~J} / \mathrm{kg} \mathrm{K}$, and based on these, we estimate a thermal diffusivity of $a=$ $45 \mathrm{~m}^{2} /$ year $\left(1.43 \times 10^{-6} \mathrm{~m}^{2} / \mathrm{s}\right)$. For both formations, Molasse and moraine sediments, the mean thermal diffusivities are similar. In a sensitivity analysis, we examined the influence of varying the thermal transport parameters within realistic ranges (e.g., $\rho=2900-2400 \mathrm{~kg} / \mathrm{m}^{3}$ ). Since such ranges are relatively small, these parameters, however, exert only a minor influence on the simulated T-logs. 


\subsection{Configuration of case-specific models}

Close to the ground surface, the temperatures of all four boreholes indicate deviations from the nearly linear trends prevailing at greater depths. For our analysis, we ignore the top $20 \mathrm{~m}$ in order to avoid seasonal influences from the atmosphere. A straight line was fitted to the non-distorted deeper part $(>120 \mathrm{~m})$ of each T-log. This yields the background geothermal gradient $(k)$ and an expected non-disturbed initial ground surface temperature, $T_{\mathrm{S}}$. The values of these parameters are listed in Table 1. It is shown that the results for the South and Southeaster location are comparable, but at the East site a higher temperature, $T_{\mathrm{S}}$, and at the Central site, a more pronounced geothermal gradient, $k$, is computed. Still, the calculated values of $T_{\mathrm{S}}=9.9-10.7{ }^{\circ} \mathrm{C}$ and $k=3.0-3.6^{\circ} \mathrm{C} / 100 \mathrm{~m}$ are within a tight and expected range. Based on initial SAT of $7.93{ }^{\circ} \mathrm{C}$, values of $\mathrm{T}_{\mathrm{G}-\mathrm{S}}$, are between 1.62 and $2.72{ }^{\circ} \mathrm{C}$ (Table 1). This is within the range reported in the regional analysis by (Signorelli and Kohl, 2004).

For each location, the geometries of buildings and historical land use changes can be delineated from publically available geographical data, cadastral maps, and orthophotos (Swisstopo, 2015). A sufficiently broad radius (up to $200 \mathrm{~m}$ ) around the boreholes was discretized, in order to simulate close-by effects such as from adjacent buildings as well as from distant heat sources such as roads and highways. For visualization in Figure 5, we chose three colours for the corresponding land use types: asphalt and paved ground (blue), buildings (red) and non-built-up areas (grey). Older buildings and streets are marked by darker colours. At two sites, the ones in the South and Southeast, we further distinguish zones in the vicinity (dotted) and at greater distance of the borehole. The boundaries between these two zones were set arbitrarily. Major questions here are, how far is the radius of influence for the T-logs, and what role do distant heat sources play? We will address this by comparing the contributions by the inner and outer zones to the distortion of the profiles. 


\subsection{Implementation of Bayesian inversion}

During Bayesian inversion, the values of $\Delta T_{a}$ (asphalt) and $T_{B}$ (buildings) are randomly generated from truncated Gaussian distributions within predefined ranges. For $\Delta T_{a}$ this range is set between $0{ }^{\circ} \mathrm{C}$ and $10{ }^{\circ} \mathrm{C}$, and $T_{B}$ is between $10{ }^{\circ} \mathrm{C}$ and $25^{\circ} \mathrm{C}$. These rather wide ranges are intended to cover an equally broad decision space for all locations and to mitigate boundary effects during stochastic sampling. The standard deviations of these distributions are also predefined. They are tuned by preliminary testing with randomly initialized MCMC chains, and set to avoid local trapping and achieve fast convergence. The standard deviations set for decision parameters are listed in Table 2.

During a particular chain, pairs of $\left(\Delta T_{a}, T_{B}\right)$ are iteratively sampled, and for each pair the analytically simulated T-logs are compared with the measured ones. As a measure of fit, the root mean squared error (RMSE) is computed. It is assumed that the likelihood of the RMSE values follows a semi-Gaussian distribution with zero mean (best possible fit) and with a standard deviation that is specific for each location-specific model (Table 2).

A new sample $\left(\Delta T_{a}, T_{B}\right)$ in the MCMC chain is proposed after updating only one of both parameters (randomly chosen in each iteration). Then the corresponding likelihood is calculated and the standard MHS acceptance/rejection ratio is applied. By assigning higher frequencies to combinations $\left(\Delta T_{a}, T_{B}\right)$ that maximize the likelihood function (RMSE close to zero), the algorithm promotes favourable model settings. Typically, a chain consists of thousands of iterations in order to ensure convergence. For the four case-specific models, we obtained stable results for the probability density functions of $\left(\Delta T_{a}, T_{B}\right)$ after about 50,000 iterations.

\section{Results}




\subsection{Measured T-logs}

The four measured T-logs are shown in Figure 6 for depths of $20-140 \mathrm{~m}$. In these depths, all logs show positive departures from the expected linear profile near the ground surface, arriving at GSTs that are several degrees warmer than the concurrent SAT of around $10{ }^{\circ} \mathrm{C}$. Taking the temperature trend of $\mathrm{GST}_{\text {out }}$ for each location, we can simulate the expected ground thermal conditions due to climate forcing. The relative effect is calculated by comparing with the initial conditions given by $T_{o}$ as reference. It is minimal at the South site with a difference of $0.8{ }^{\circ} \mathrm{C}$ at $20 \mathrm{~m}$ depth. For the East and Southeast locations, the ground warms up by around $1.0{ }^{\circ} \mathrm{C}$, while at the Central site, a change of $1.2{ }^{\circ} \mathrm{C}$ is derived. Even when approximating GSTs as shifted SAT (by adding $\Delta T_{G-S}$, Table 1), it is clear that additional heat sources at the ground surface must exist that have long-term effects on the thermal regime in the ground. For example, at the Central location, the measured temperatures reach nearly $15{ }^{\circ} \mathrm{C}$ at $20 \mathrm{~m}$ depth. This upper value is at least $1.5{ }^{\circ} \mathrm{C}$ lower at the other locations and only around $12.5{ }^{\circ} \mathrm{C}$ in the South. These differences correspond well with the intensity of urbanization, which is highest in the Central area.

The plots in Figure 6 also show the linearly extrapolated non-distorted GST trend $\left(T_{o}\right)$. The site-specific conditions yield different values for $T_{S}$ as listed in Table 1. The differences are most probably due to case-specific coupling between SAT and GST, but they could also indicate other factors. Our fundamental assumption is that the conditions before 1880 can be approximated by an undisturbed thermal equilibrium. However, the city of Zurich existed already earlier and associated anthropogenic land use changes may have impacted the ground thermal regime before. With the limited information available for earlier times, however, we will not examine further the reasons for the different initial modelling conditions. Note that our analysis of recent developments focuses on relative changes, which are caused by factors that superpose to the background conditions. 
The onset of deviation from the linear trends is slightly different at each site (Figure 6), and it can only roughly be determined. At Southeast and Central, it is at around $120 \mathrm{~m}$, at East, approximately $90 \mathrm{~m}$ and at South, around $100 \mathrm{~m}$. Generally, when compared to the expected temperature profile from climate forcing only, we see earlier deviation in the measured $\mathrm{T}$ logs. This reveals that climate change effects as measured in the SAT time series set in later than those from land use changes at the sites.

\subsection{Inverted T-logs}

Given measurement errors and other noise in the recorded data, there often exists a set of near optimal solutions that are similarly acceptable. Aside from this, at the ground surface of all locations, many superpositioned heat sources exist and even if we invert only universal values of asphalt and buildings, the inversion problems are hardly well-posed. We are therefore not interested in finding a single global optimum. The Bayesian approach exhaustively explores the decision space and we can extract the set of all those solutions providing an acceptable fit. After MCMC search, we visualized the results and compared the best solutions to the measured data. Then, only combinations of $\left(\Delta T_{a}, T_{B}\right)$ with RMSE of lower than $0.1{ }^{\circ} \mathrm{C}$ were kept, except for the Central site, where model fitting was less successful and the tolerance was increased to $0.3^{\circ} \mathrm{C}$.

In Figure 7 , the correlated ranges of acceptable $\left(\Delta T_{a}, T_{B}\right)$ combinations are shown. For the Southeast and East locations, the mathematically feasible combinations span the entire parameter value ranges with a clear linear correlation. At these locations, the timing of most thermally influencing buildings and pavements is fairly similar (Figure 5a,c). Due to superpositioning of both heat sources, the resulting $T_{B}$ and $\Delta T_{a}$ are inversely proportional. At the East location for instance, we can obtain the same profile through the increase of $\Delta T_{a}$ by $1.0{ }^{\circ} \mathrm{C}$ and by decreasing $T_{B}$ by $0.6{ }^{\circ} \mathrm{C}$. 
For the South and Central locations, the resulting values also indicate inverse proportionality, but the ranges shown in Figure 7 are limited. For the South location, $T_{B}$ should be higher than $14{ }^{\circ} \mathrm{C}$ and $\Delta T_{a}$ lower than $5{ }^{\circ} \mathrm{C}$. For the Central site these limits are $14.6{ }^{\circ} \mathrm{C}$ and $5.1{ }^{\circ} \mathrm{C}$, respectively. The resulting parabolic shape in Figure 7 is attributed to the different timing of heat sources. In contrast to the Southeast and East sites, the life time of buildings and pavements varies significantly at the South and Central locations. At the South for instance, streets are old compared to the most influencing buildings in vicinity of the borehole (Figure 5b,d). This means that pavements considerably affect deep subsurface temperatures here. In other words, a $\Delta T_{a}$ higher than $5.1^{\circ} \mathrm{C}$ would imply a deeper thermal anomaly that is not seen in the measured T-log. However, a $T_{B}$ lower than $14.6{ }^{\circ} \mathrm{C}$ is insufficient to yield the relatively high temperatures in the shallow regime. In essence, both land use types control different depths in the T-logs and their effects can be better separated than for the other locations.

Taking all combinations $\left(\Delta T_{a}, T_{B}\right)$ that delineate the different areas in Figure 7 for the given RMSE thresholds, we obtain the modelled T-logs presented as grey bands in Figure 6. For all sites, the measured data is well covered, with better fit for the East, South and Southeast locations. The Central site requires a broad tolerance, which also provides some insight into the limitations of the model for this specific case. According to Figure 6d, the relative high GST is reached by the right envelope of the grey band, which is associated with an extreme combination of $T_{B}=19.1{ }^{\circ} \mathrm{C}, \Delta T_{a}=0{ }^{\circ} \mathrm{C}$ (Figure 7). Yet this high value of $T_{B}$ also yields overestimated temperatures in the deeper profile. In comparison, the left envelope $\left(T_{B}=15.8\right.$ ${ }^{\circ} \mathrm{C}, \Delta T_{a}=0{ }^{\circ} \mathrm{C}$ ) matches closely to the measured $\mathrm{T}-\log$ starting at $70 \mathrm{~m}$ depth, but the simulated temperatures are up to $1{ }^{\circ} \mathrm{C}$ cooler above. Any other combinations with more realistic values, $\Delta T_{a}>0{ }^{\circ} \mathrm{C}$ and $\mathrm{RMSE}<0.3{ }^{\circ} \mathrm{C}$, yield intermediate profiles that underestimate shallow temperatures and overestimate those at greater depths. 
The unmatched high temperatures, especially in the shallow zone of the Central location, are probably induced by additional heat sources not accounted for in the proposed model. In urbanized areas like the Rämistrasse in Zurich, district heating networks and sewage systems may contribute to subsurface urban warming as observed in other cities (Menberg et al., 2013b). Even though such factors could be implemented in the analytical model as nodal/line/planar sources with a defined heat rate (Rivera et al., submitted), this is not done here. The required temperature measurements to describe long-term effects of such infrastructures are not available.

The wide range of acceptable value pairs $\left(\Delta T_{a}, T_{B}\right)$ in Figure 7 can be further constrained by findings from previous work. According to the measurements by Dědeček et al. (2012) in Prague, plausible values for $\Delta T_{a}$ are between 3 and $4{ }^{\circ} \mathrm{C}$. Benz et al. (2015b) suggest a rough range of $15{ }^{\circ} \mathrm{C}<T_{B}<20{ }^{\circ} \mathrm{C}$ for basements of buildings in the cities of Cologne and Karlsruhe. A zoomed view of the resulting solution space is also shown in Figure 7. It indicates that the window with $T_{B}=15-16{ }^{\circ} \mathrm{C}$ and $\Delta T_{a}=3-3.5^{\circ} \mathrm{C}$ can be considered as a universally valid solution for all locations. Nevertheless, a lumped $\Delta T_{a}$ between 3 and $4{ }^{\circ} \mathrm{C}$ may be realistic for younger pavements such as those found at the South and Southeast locations (i.e. parking lots around buildings). Older streets may be better represented by a transient trend, for instance, by assigning bare soil characteristics at earlier times. Potentially, $\Delta T_{a}$ slightly increases with the rising temperature in the atmosphere. This could be also one of the reasons for the unsatisfactory fit for T-log of the Central location. Here, influential streets date back to 1880 , and have likely not been completely asphalted since that time.

Similarly, by assuming a lumped value for $T_{B}$, we neglect not only potential spatial variability but also temporal trends. Among these are time-dependent changes in the indoor temperature due to different cooling/heating patterns or changes in building use, as well as recent efforts for improved insolation of basements. Such spatial and temporal heterogeneity can hardly be 
inferred from single T-log inversion, but could be examined for instance by repeated measurements of multiple neighbouring boreholes. Such measurements, however, are not available so far.

\subsection{Role of land use types and lateral distance to borehole}

In this section, we shed light on the different land use characteristics of each site and how these are reflected in the T-logs. This also includes an analysis of the role of distant land use variations, with a focus on the South and Southeast locations. For conciseness, we focus on the value ranges suggested by Dědeček et al. (2012) and Benz et al. (2015b) (Figure 7).

The Southeast location represents a typical old residential agglomeration with significant urbanization. Next to the borehole, we find buildings and paved ground dating back to 1959 (age of 46 years in 2005, Figure 5a). At a range of around $30-70 \mathrm{~m}$ to the northwest, five old buildings had been constructed in 1885, two of which have already been demolished in 1959 . These were located at around the same spot as the (newer) building closest to the borehole in the southern direction. Also, most of the streets already existed before 1900 .

From Figure 7 we extract those acceptable models with $T_{B}$ between 15 and $16.5{ }^{\circ} \mathrm{C}$ and $\Delta T_{a}$ between 3 and $3.7{ }^{\circ} \mathrm{C}$. Implementing these ranges in the model, we can contrast the relative contribution by all asphalted areas and all built-up areas to the simulated T-logs. For the Southeast location, Figure 8a depicts the envelopes of the relative contributions. The depthdependent graph shows that the buildings contributed to the urban heating of the deeper ground by only around $40-55 \%$. This is even less towards the ground surface at only about $20-40 \%$. The reason for this depth-dependent variation must be found at the ground surface. Here, the borehole is located within asphalted ground that dominates the near-surface conditions. The influence from the surrounding buildings, especially of old ones, rises with depth. 
In comparison, the result for the South location, with its relatively young built-up structures (Figure 5b), is illustrated in Figure 8b. Here the buildings are mainly for commercial/industrial use and accordingly, Figure 7 suggests broader ranges and higher values for $T_{B}=15-17.5^{\circ} \mathrm{C}$, and for $\Delta T_{a}=3-4{ }^{\circ} \mathrm{C}$. By implementing these ranges in the model, Figure $8 \mathrm{~b}$ shows that the relative contribution by buildings increases towards the ground surface and reaches more than $60 \%$ (in contrast to around $20 \%$ in $140 \mathrm{~m}$ depth). A major factor is the relatively young building next to the borehole, which was constructed in 1999 (Figure 5b). Further, buildings at around 100 m radius date back to 1962 and most of the other buildings in this area stem from the 1960s and 1970s (age of 40-50 years). These all represent substantial and recently active heat sources. Several streets have existed already since 1900 (>100 years old) in this area. The striking highway crossing the western part of the mapped area (from 1965) may act as crucial heat source, but is at a further distance than the adjacent buildings. These observations for the South and Southeast location elucidate the prominent role of those structures dominating the land use nearby a measurement location. These contribute mainly to the ground heating in shallow depth. While this is rather logical, this analysis also emphasizes the deep penetrating contribution from old and distant structures.

In order to investigate the radius of influence for the measured T-logs in more detail, we distinguish an inner and an outer area for the two focal sites. The structures belonging to the inner area are in the vicinity of the borehole and marked by dashed borders in Figure 5a,b. For conciseness, the relative contributions for the two land use types are exclusively shown for a moderate value of $\Delta T_{a}=3.5{ }^{\circ} \mathrm{C}$, with $T_{B}$ set to $15.5^{\circ} \mathrm{C}$ for the Southeast location and $17{ }^{\circ} \mathrm{C}$ for the South location (Figure 7). For the latter, Figure 9b shows that the relative contribution of distant land use changes are only marginal. Despite a slight increase towards depth, paved 
ground and built-up areas contribute less than $20 \%$ cumulatively. The major reason for this is that most buildings, which dominate the outer area, are younger than 50 years (Figure $5 b$ ).

The Southeast location yields somewhat different results. While the paved ground in the vicinity of the borehole is the most important contributor to the distortion of the T-log, with increase of depth, the relative role of structures in the outer area becomes more important. This is clearly due to the presence of many buildings that have been in existence for a long time. An increasing relevance towards depth is attributed to more distant streets. One major factor for this is that streets at this location date back to 1900 .

The percentages shown in Figures 8 and 9 correspond to the urban effect, which is restricted to changes in GST. This effect can be interpreted as subsurface urban heat island intensity (Lokoshchenko and Korneva, 2015; Menberg et al., 2013a) and is computed from the difference between the simulated profile bands and the profile associated with climate forcing (see Figure 6). This difference is obviously maximal close to the ground reaching magnitudes between 0.75 (East) and $2.4{ }^{\circ} \mathrm{C}$ (Central) at a depth of $20 \mathrm{~m}$. With increasing depth, the urban effect declines, and thus at greater depth, the relative contributions shown in Figure 8 and 9 indicate only a marginal urban effect.

\subsection{Additional energy stored in the ground}

As an alternative to the depth-dependent urban heat island intensity, we can compute as integral value the additionally stored energy, $E(z, t)=\int_{0}^{z} \rho c \cdot\left[T(h, t)-T_{o}(h, t)\right] d h$. The values associated with the increase of the background temperature (GST ${ }_{\text {out }}$ ) are compared to those related to urban land use changes. We focus only on the energy below $20 \mathrm{~m}$. Table 3 demonstrates that background values are mostly moderate and comparable between 30 and 43 $\mathrm{MJ} / \mathrm{m}^{2}$. For the Central location, however, the inferred contribution is $66 \mathrm{MJ} / \mathrm{m}^{2}$. This may be an indicator for special site conditions, local atmospheric urban heating or, as discussed 
above, already perturbed initial conditions. With the strong ground heating shown in the profile in Figure $6 \mathrm{~d}$, the Central location also reveals a significant contribution from urban structures. Based on the measured profile, it reaches $151 \mathrm{MJ} / \mathrm{m}^{2}$. As expected, the stored "urban energy" is higher in the older residential area in the Southeast than in the younger South. The East location represents an outlier, with relative small urban contributions. This reveals the role of the relatively low building intensity and the few heat sources present at this location.

For illustration of the transient trends, Figure 10 shows the amount of energy cumulating in the ground, which originates from urban structures (and thus excluding natural heat flux). For each site, a trend is obtained for simulation with one representative combination of $\Delta T_{a}$ and $T_{B}$. Based on Figure 7, we chose $\Delta T_{a}=3.5^{\circ} \mathrm{C}$ and $T_{B}=17{ }^{\circ} \mathrm{C}$ for South, East and Central location, while keeping $T_{B}=15.5^{\circ} \mathrm{C}$ for the Southeast site as specified for Figure 5 .

Abrupt changes in Figure 10 indicate the times when new structures appeared. Finally, the curves arrive at values that are within the ranges listed in Table 3 for the simulated contribution by urban structures. Accordingly, the Central and Southeast sites are clearly more affected by urbanization. At early times, the cumulated energy is higher at the Southeast site due to the influence from very old buildings in the vicinity of the borehole. Those buildings were demolished in 1959 leading to a temporal release of the stored energy through the ground surface. This is reflected by a declining trend of the energy stored. During the last decades, this however was compensated by new buildings and asphalted areas.

At the Central site, mainly asphalted ground yielded energy input at early times. These areas are relatively distant from the borehole, when compared to the most influential buildings that were built between 1936 and 1958. Overall, the urbanization process and growth of built-up area was clearly faster than at the other sites, explaining the strong increase in the stored energy. 
The South and East sites are less urbanized areas and therefore, a lower amount of stored energy is expected. At the South site for instance, some of the surrounding buildings were constructed in 1962, while the closest one was built in 1999. Both events are reflected in the abrupt steepening of the cumulated energy. In contrast, the East site exhibits a rather monotonic increase. This is mainly driven by the permanent contribution by surrounding asphalted areas which date back to 1905 . Here, most of the surrounding buildings were built after 1980.

\section{Conclusions}

The main new contribution of our work is that temporal and spatial land use changes are included in the analytical inversion of temperature profiles (T-logs). Most related studies in borehole climatology focus on backtracking of climatic changes where land use changes are unfavourable. We demonstrate that T-logs measured in urban environments show perturbations that can be quantitatively related with the lifetime of buildings and asphalted streets in the vicinity of the measurement locations. This is because urban structures raise heat fluxes in the ground, which here is simulated by increased temperatures at the top boundary of the three-dimensional analytical model.

The presented inversion problem is necessarily dependent on several parameters which are unknown, and reliable backtracking of past land use effects is only feasible when considerable knowledge of developments and changes in the past are available, such as building histories and ground surface temperature evolution. Even for the well documented case study in the urban area of Zurich presented here, however, we made several simplifying assumptions to carry out the inversion. We distinguished only two urban land use types, buildings and asphalted ground, and assumed that these can be described by universal parameters. Still, 
further analysis would be necessary to investigate the role of heterogeneous land use types on T-logs and the identifiability of parameters in the inversion.

The Bayesian approach used for the inversion in this work delivers a possible set of results and gives insight into potential parameter correlations. This is crucial for exploring the range of feasible solutions, which would not be possible by deterministic calibration. For the four locations, plausible results for characteristic temperatures for buildings and asphalt are derived. Even if site-specific results may be broader, buildings can be generally described by a constant temperature of $15-16{ }^{\circ} \mathrm{C}$, and asphalt in this climate zone by an increase of temperature by $3-3.5{ }^{\circ} \mathrm{C}$ in comparison to unsealed land for asphalt. At locations with higher urbanization, however, additional heat sources such as sewage and district heating systems appear to be relevant.

The presented inverse modelling framework does not allow only backtracking of past changes, but could be used for local and even city-wide predictions of the future thermal conditions in the ground. This is of interest to envisage the long-term evolution of subsurface urban heat islands (UHIs), and especially their spatial development and associated geothermal potential. This also allows for the comparison of the roles of urbanization and climate change on ground thermal conditions. For the study case of Zurich, for instance, it was revealed that in most cases, urban structures are the major contributors to the additional accumulated energy in the subsurface. Climate change, however, which is the subject of most borehole temperature inversions, is a secondary cause.

\section{Acknowledgements}

This work was supported by the Swiss National Science Foundation (SNSF) under grant number 200021L 144288. We thank Rachael Colldeweih for language corrections. The 
comments by Rob Westaway and two anonymous reviewers helped improving the manuscript.

\section{References}

Arola, T., and K. Korkka-Niemi, 2014, The effect of urban heat islands on geothermal potential: examples from Quaternary aquifers in Finland: Hydrogeology Journal, v. 22, p. 1953-1967.

Barkaoui, A.-E., A. Correia, Y. Zarhloule, A. Rimi, J. Carneiro, M. Boughriba, and M. Verdoya, 2013, Reconstruction of remote climate change from borehole temperature measurement in the eastern part of Morocco: Climatic change, v. 118, p. 431-441.

Bense, V., and H. Beltrami, 2007, Impact of horizontal groundwater flow and localized deforestation on the development of shallow temperature anomalies: Journal of Geophysical ResearchEarth Surface, v. 112.

Benz, S. A., P. Bayer, K. Menberg, S. Jung, and P. Blum, 2015a, Spatial resolution of anthropogenic heat fluxes into urban aquifers: Science of The Total Environment, v. 524-525, p. 427-439.

Benz, S. A., P. Bayer, K. Menberg, S. Jung, and P. Blum, 2015b, Spatial resolution of anthropogenic heat fluxes into urban aquifers: Science of The Total Environment, v. 524, p. 427-439.

Bodri, L., and V. Cermak, 2011, Borehole climatology: a new method how to reconstruct climate, Elsevier.

Carslaw, H., and J. Jaeger, 1959, Conduction of Heat in Solids: New York, Oxford University Press.

Davis, M. G., R. N. Harris, and D. S. Chapman, 2010, Repeat temperature measurements in boreholes from northwestern Utah link ground and air temperature changes at the decadal time scale: Journal of Geophysical Research: Solid Earth (1978-2012), v. 115.

Dědeček, P., J. Šafanda, and D. Rajver, 2012, Detection and quantification of local anthropogenic and regional climatic transient signals in temperature logs from Czechia and Slovenia: Climatic change, v. 113, p. 787-801.

Dutra, E., C. Schär, P. Viterbo, and P. Miranda, 2011, Land-atmosphere coupling associated with snow cover: Geophysical Research Letters, v. 38.

Epting, J., F. Händel, and P. Huggenberger, 2013, Thermal management of an unconsolidated shallow urban groundwater body: Hydrology and Earth System Sciences, v. 17, p. 1851-1869.

Ferguson, G., and H. Beltrami, 2006, Transient lateral heat flow due to land-use changes: Earth and Planetary Science Letters, v. 242, p. 217-222.

Ferguson, G., and A. D. Woodbury, 2004, Subsurface heat flow in an urban environment: Journal of Geophysical Research-Solid Earth, v. 109.

Goto, S., M. Yamano, H. Kim, Y. Uchida, and Y. Okubo, 2009, Ground surface temperature history reconstructed form borehole temperature data in Awaji Island, southwest Japan for studies of human impacts on climate change in East Asia: From headwaters to the ocean: hydrological changes and watershed management. Taylor \& Francis, London, p. 529-534.

Harris, R. N., and D. S. Chapman, 1997, Borehole temperatures and a baseline for 20th-century global warming estimates: Science, v. 275, p. 1618-1621. 
Hartmann, A., and V. Rath, 2005, Uncertainties and shortcomings of ground surface temperature histories derived from inversion of temperature logs: Journal of Geophysics and Engineering, v. 2, p. 299.

Hastings, W. K., 1970, Monte Carlo sampling methods using Markov chains and their applications: Biometrika, v. 57, p. 97-109.

Herb, W. R., B. Janke, O. Mohseni, and H. G. Stefan, 2008, Ground surface temperature simulation for different land covers: Journal of Hydrology, v. 356, p. 327-343.

Herbert, A., S. Arthur, and G. Chillingworth, 2013, Thermal modelling of large scale exploitation of ground source energy in urban aquifers as a resource management tool: Applied Energy, v. 109, p. 94-103.

Hopcroft, P. O., K. Gallagher, C. C. Pain, and F. Fang, 2009, Three-dimensional simulation and inversion of borehole temperatures for reconstructing past climate in complex settings: J. Geophys. Res., v. 114, p. F02019.

Huang, S., H. N. Pollack, and P.-Y. Shen, 2000, Temperature trends over the past five centuries reconstructed from borehole temperatures: Nature, v. 403, p. 756-758.

Huang, S., M. Taniguchi, M. Yamano, and C. H. Wang, 2009, Detecting urbanization effects on surface and subsurface thermal environment -- A case study of Osaka: Science of The Total Environment, v. 407, p. 3142-3152.

Kataoka, K., F. Matsumoto, T. Ichinose, and M. Taniguchi, 2009, Urban warming trends in several large Asian cities over the last 100 years: Science of The Total Environment, v. 407, p. 31123119.

Kohl, T., 1999, Transient thermal effects below complex topographies: Tectonophysics, v. 306, p. 311324.

Kooi, H., 2008, Spatial variability in subsurface warming over the last three decades; insight from repeated borehole temperature measurements in The Netherlands: Earth and Planetary Science Letters, v. 270, p. 86-94.

Kurylyk, B. L., and K. T. MacQuarrie, 2014, A new analytical solution for assessing climate change impacts on subsurface temperature: Hydrological Processes, v. 28, p. 3161-3172.

Lachenbruch, A. H., and B. V. Marshall, 1986, Changing climate: geothermal evidence from permafrost in the Alaskan Arctic: Science, v. 234, p. 689-696.

Lewis, T. J., and K. Wang, 1992, Influence of terrain on bedrock temperatures: Global and planetary change, v. 6, p. 87-100.

Lokoshchenko, M., and I. Korneva, 2015, Underground urban heat island below Moscow city: Urban Climate, v. 13, p. 1-13.

Mann, M. E., and G. A. Schmidt, 2003, Ground vs. surface air temperature trends: Implications for borehole surface temperature reconstructions: Geophysical Research Letters, v. 30.

Mareschal, J.-C., and H. Beltrami, 1992, Evidence for recent warming from perturbed geothermal gradients: examples from eastern Canada: Climate Dynamics, v. 6, p. 135-143.

Menberg, K., P. Bayer, K. Zosseder, S. Rumohr, and P. Blum, 2013a, Subsurface urban heat islands in German cities: Science of the total environment, v. 442, p. 123-133.

Menberg, K., P. Blum, A. Schaffitel, and P. Bayer, 2013b, Long-Term Evolution of Anthropogenic Heat Fluxes into a Subsurface Urban Heat Island: Environmental science \& technology, v. 47, p. 9747-9755.

MeteoSchweiz, 2015, The Federal Office of Meteorology and Climatology. 
Metropolis, N., A. W. Rosenbluth, M. N. Rosenbluth, A. H. Teller, and E. Teller, 1953, Equation of state calculations by fast computing machines: The journal of chemical physics, v. 21, p. 1087-1092.

Nitoiu, D., and H. Beltrami, 2005, Subsurface thermal effects of land use changes: Journal of Geophysical Research-Earth Surface, v. 110.

Pollack, H. N., and S. P. Huang, 2000, Climate reconstruction from subsurface temperatures: Annual Review of Earth and Planetary Sciences, v. 28, p. 339-365.

Reiter, M., 2006, Vadose zone temperature measurements at a site in the northern Albuquerque Basin indicate ground-surface warming due to urbanization: Environmental \& Engineering Geoscience, v. 12, p. 353-360.

Reiter, M., 2007, Variability of recent ground surface temperature changes in the Albuquerque basin, central New Mexico: Journal of Geophysical Research: Atmospheres (1984-2012), v. 112.

Rivera, J. A., P. Blum, and P. Bayer, 2015, Analytical simulation of groundwater flow and land surface effects on thermal plumes of borehole heat exchangers: Applied Energy, v. 146, p. 421-433.

Rivera, J. A., P. Blum, and P. Bayer, Under review, Influence of spatially variable ground heat flux on geothermal systems: Line source model with nonhomogeneous Cauchy-type top boundary conditions: Applied Energy.

Rohner, E., L. Rybach, and U. Schärli, 2005, A new, small, wireless instrument to determine ground thermal conductivity in-situ for borehole heat exchanger design: Proceedings World Geothermal Congress 2005.

Schärli, U., E. Rohner, S. Signorelli, and R. Wagner, 2007, Thermische Leitfähigkeit: Eichung von in-situ Messungen (dh „kabellose Temperatursonde ") mit Laborbestimmungen als Grundlage für die geothermische Kartierung des Kanton ZH und der umliegenden Kantone: Bundesamt für Energie, Bern.

Signorelli, S., and T. Kohl, 2004, Regional ground surface temperature mapping from meteorological data: Global and Planetary Change, v. 40, p. 267-284.

Smerdon, J. E., H. N. Pollack, J. W. Enz, and M. J. Lewis, 2003, Conduction-dominated heat transport of the annual temperature signal in soil: Journal of Geophysical Research-Solid Earth, v. 108.

Stauffer, F., P. Bayer, P. Blum, N. M. Giraldo, and W. Kinzelbach, 2013, Thermal use of shallow groundwater, CRC Press.

Swisstopo, 2015, Amtliche Vermessung Zürich.

Taniguchi, M., J. Shimada, Y. Fukuda, M. Yamano, S. Onodera, S. Kaneko, and A. Yoshikoshi, 2009, Anthropogenic effects on the subsurface thermal and groundwater environments in Osaka, Japan and Bangkok, Thailand: Science of the Total Environment, v. 407, p. 3153-3164.

Taniguchi, M., J. Shimada, T. Tanaka, I. Kayane, Y. Sakura, Y. Shimano, S. Dapaah-Siakwan, and S. Kawashima, 1999, Disturbances of temperature-depth profiles due to surface climate change and subsurface water flow: 1 . An effect of linear increase in surface temperature caused by global warming and urbanization in the Tokyo metropolitan area, Japan: Water Resources Research, v. 35, p. 1507-1517.

Taniguchi, M., T. Uemura, and K. Jago-on, 2007, Combined effects of urbanization and global warming on subsurface temperature in four Asian cities: Vadose Zone Journal, v. 6, p. 591596.

Taniguchi, M., T. Uemura, and Y. Sakura, 2005, Effects of urbanization and groundwater flow on subsurface temperature in three megacities in Japan: Journal of Geophysics and Engineering, v. 2, p. 320-325. 
Vogt, C., D. Mottaghy, V. Rath, G. Marquart, L. Dijkshoorn, A. Wolf, and C. Clauser, 2014, Vertical variation in heat flow on the Kola Peninsula: palaeoclimate or fluid flow?: Geophysical Journal International, v. 199, p. 829-843.

Yamano, M., 2011, Evolution of the Subsurface Thermal Environment in Urban Areas: Studies in Large Cities in East Asia, Groundwater and Subsurface Environments, Springer, p. 201-230.

Yamano, M., S. Goto, A. Miyakoshi, H. Hamamoto, R. F. Lubis, V. Monyrath, and M. Taniguchi, 2009, Reconstruction of the thermal environment evolution in urban areas from underground temperature distribution: Science of the total environment, v. 407, p. 3120-3128.

Zhu, K., P. Bayer, P. Grathwohl, and P. Blum, 2014, Groundwater temperature evolution in the subsurface urban heat island of Cologne, Germany: Hydrological Processes.

Zhu, K., P. Blum, G. Ferguson, K.-D. Balke, and P. Bayer, 2010, The geothermal potential of urban heat islands: Environmental Research Letters, v. 5, p. 044002. 


\section{Tables}

Table 1. Dates, locations, depths and elevations of borehole measurements, with linearly interpolated initial GST $\left(T_{S}\right)$, undisturbed geothermal gradient $(k)$, and shift $\Delta T_{G-S}$ between GST and SAT derived from T-log analysis.

\begin{tabular}{|c|c|c|c|c|c|c|c|}
\hline Location & $\begin{array}{l}\text { Coordinates } \\
\text { (WGS 84) }\end{array}$ & Date & Elevation & Depth & $\boldsymbol{T}_{S}$ & $k$ & $\Delta T_{G-S}$ \\
\hline & & & (m a.s. 1.) & (m) & $\left({ }^{\circ} \mathrm{C}\right)$ & $\left({ }^{\circ} \mathrm{C} / 100 \mathrm{~m}\right)$ & $\left({ }^{\circ} \mathrm{C}\right)$ \\
\hline Southeast & $\begin{array}{l}47.26705 \mathrm{~N} \\
/ 8.65591 \mathrm{E}\end{array}$ & Oct / 2005 & 420 & 280 & 9.9 & 3.0 & 2.00 \\
\hline South & $\begin{array}{l}47.31006 \mathrm{~N} \\
\text { / } 8.54390 \mathrm{E}\end{array}$ & Sep / 2008 & 500 & 200 & 9.6 & 3.0 & 1.62 \\
\hline East & $\begin{array}{l}47.37442 \mathrm{~N} \\
/ 8.56419 \mathrm{E}\end{array}$ & Sep / 2009 & 520 & 410 & 10.7 & 3.0 & 2.72 \\
\hline Central & $\begin{array}{l}47.37086 \mathrm{~N} \\
\text { / } 8.55022 \mathrm{E}\end{array}$ & Mar / 2013 & 420 & 540 & 10.4 & 3.6 & 2.47 \\
\hline
\end{tabular}


Table 2. Standard deviations specified for decision parameters $\left(\Delta T_{a}, T_{B}\right)$ and likelihood function during Bayesian inversion.

$$
\text { standard deviation }\left({ }^{\circ} \mathrm{C}\right)
$$

\begin{tabular}{|c|c|c|c|}
\hline Location & $\Delta \boldsymbol{T}_{\boldsymbol{a}}$ & $T_{B}$ & $\begin{array}{l}\text { likelihood } \\
\text { function }\end{array}$ \\
\hline Southeast & 1 & 2 & 0.2 \\
\hline South & 2 & 3 & 0.2 \\
\hline East & 1.5 & 2.5 & 0.2 \\
\hline Central & 2 & 3 & 0.5 \\
\hline
\end{tabular}

Table 3. Energy stored additionally at four study locations beneath $20 \mathrm{~m}$ depth due to background atmospheric temperature increase and due to urbanization. The simulated contributions by urban structures are the ranges associated with the results (grey bands) shown in Figure 6.

\begin{tabular}{|c|c|c|c|c|}
\hline Location & $\begin{array}{c}\text { Measured } \\
\text { contribution by } \\
\text { atmospheric } \\
\text { warming } \\
\left(\mathrm{MJ} / \mathrm{m}^{2}\right)\end{array}$ & $\begin{array}{c}\text { Measured } \\
\text { contribution by } \\
\text { urban structures } \\
\left(\mathbf{M J} / \mathbf{m}^{2}\right)\end{array}$ & $\begin{array}{c}\text { Simulated } \\
\text { contribution by } \\
\text { urban structures } \\
\left(\mathbf{M J} / \mathbf{m}^{2}\right)\end{array}$ & $\begin{array}{c}\text { Total measured } \\
\text { additional energy } \\
\left(\mathbf{M J} / \mathbf{m}^{2}\right)\end{array}$ \\
\hline Southeast & $30(24 \%)$ & $97(76 \%)$ & $85-116$ & 127 \\
\hline South & $32(30 \%)$ & $75(70 \%)$ & $59-87$ & 107 \\
\hline East & $43(52 \%)$ & $39(48 \%)$ & $24-52$ & 82 \\
\hline Central & $66(30 \%)$ & $151(70 \%)$ & $116-218$ & 217 \\
\hline
\end{tabular}


Figures

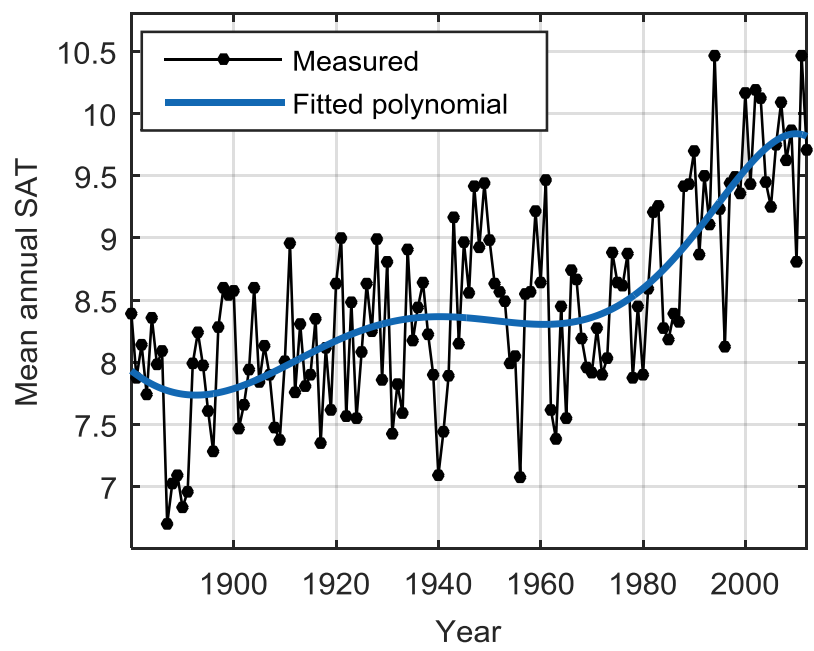

Figure 1. Annual mean and polynomial regression of surface air temperatures (SAT) measured at Fluntern, Zurich.
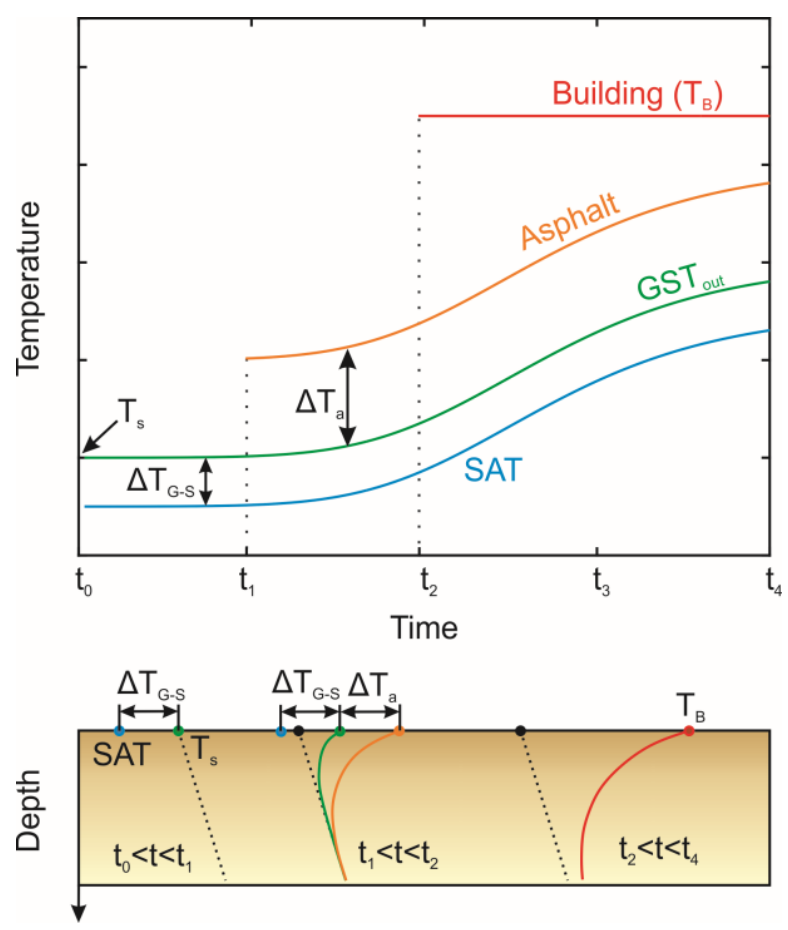

Figure 2. Schematic relationship between SAT, background $\mathrm{GST}_{\text {out }}$, shift between both $\left(\Delta T_{\mathrm{G}-\mathrm{S}}\right)$, temperature of paved ground (asphalt) and buildings. The bottom figure illustrates the effects of long term background warming $\left(\mathrm{GST}_{\text {out }}\right)$, asphalt $\left(\Delta T_{\mathrm{a}}\right)$ and buildings $\left(T_{\mathrm{B}}\right)$ on a temperature profile for arbitrary points in time. 


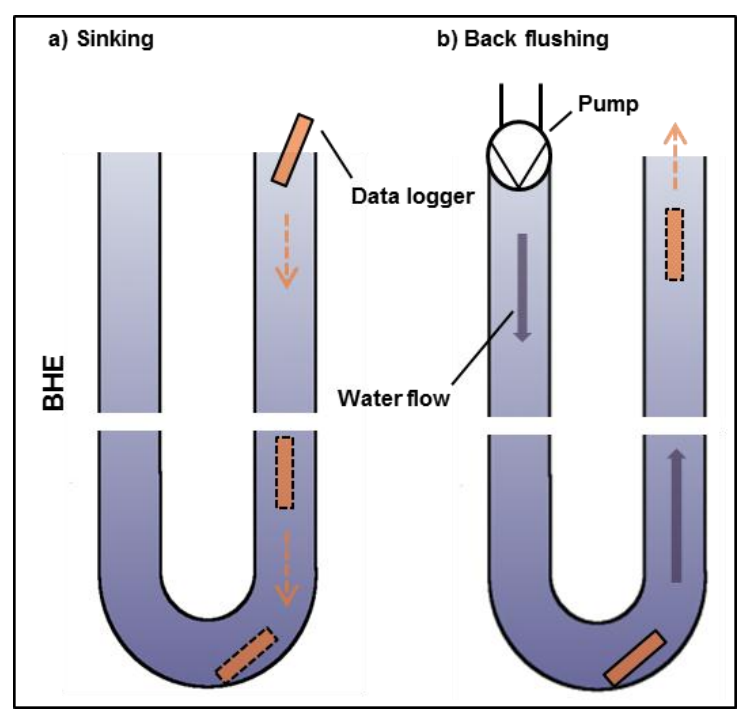

Figure 3. Illustration of wireless temperature logging in a U-tube of a borehole heat exchanger (BHE), showing (a) lowering during measurement phase, and (b) subsequent back-flushing by pumping water in counter flow. Typical vertical depth of borehole is 100 $-450 \mathrm{~m}$.

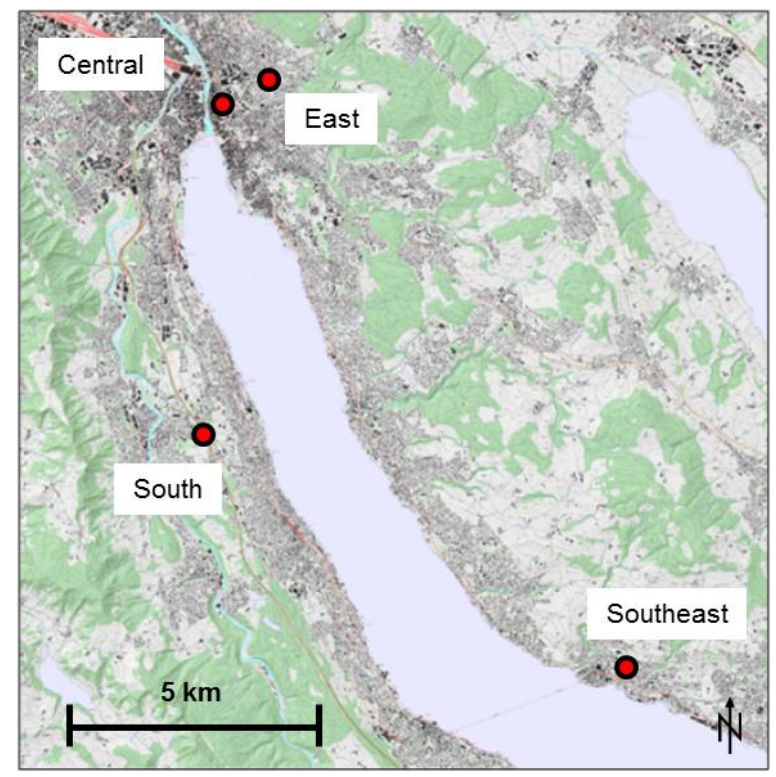

Figure 4. Locations of four boreholes in urban and suburban region of Zurich (for exact coordinates please see Table 1). 

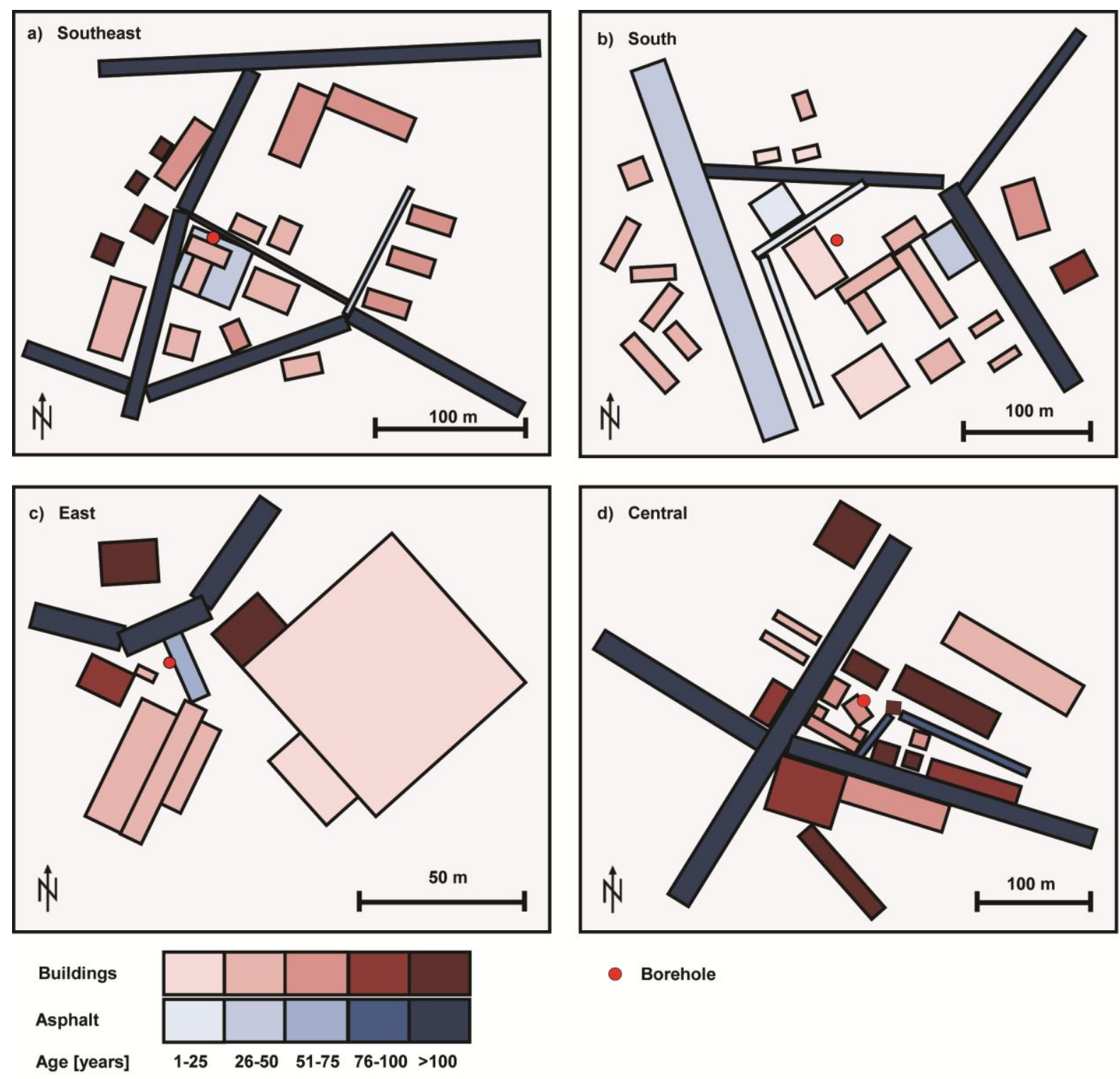

- Borehole

Figure 5. Land use maps with buildings and paved ground in the surrounding of the four boreholes, where the temperature measurements were taken. The age of each structure is reflected by color intensity, and for the Southeastern and South location, an inner (continuous) and outer zone (dashed) is distinguished for examining the effect of more distant heat sources at the ground surface. 

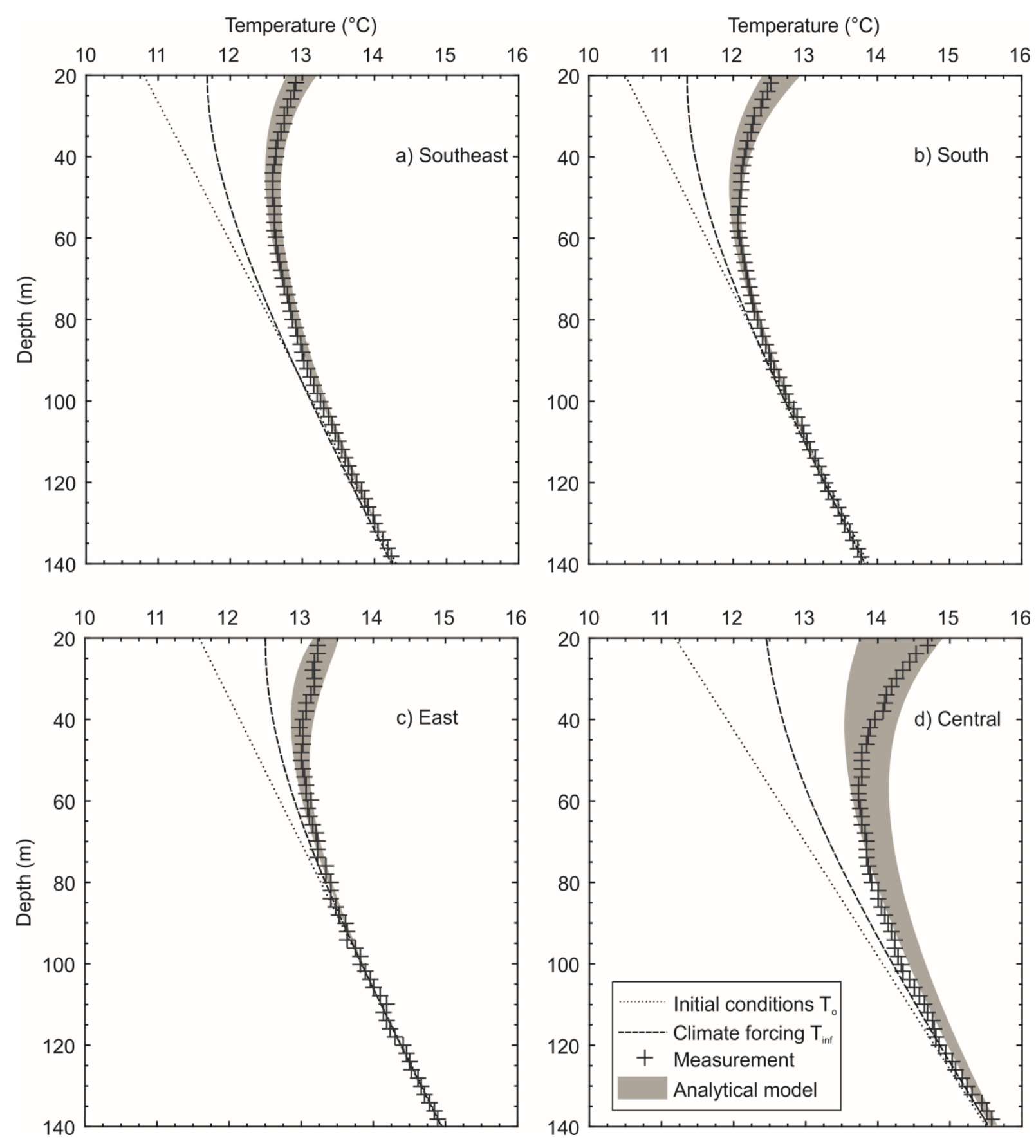

Figure 6. Measured temperature profiles (T-logs) in depth of 20-140 m with results from Bayesian inversion of analytical model (envelopes with $\mathrm{RMSE}=0.3{ }^{\circ} \mathrm{C}$ at the Central location and $\mathrm{RMSE}=0.1{ }^{\circ} \mathrm{C}$ at other sites). Also shown are undisturbed linear trends, and expected profiles due to climate forcing alone. 


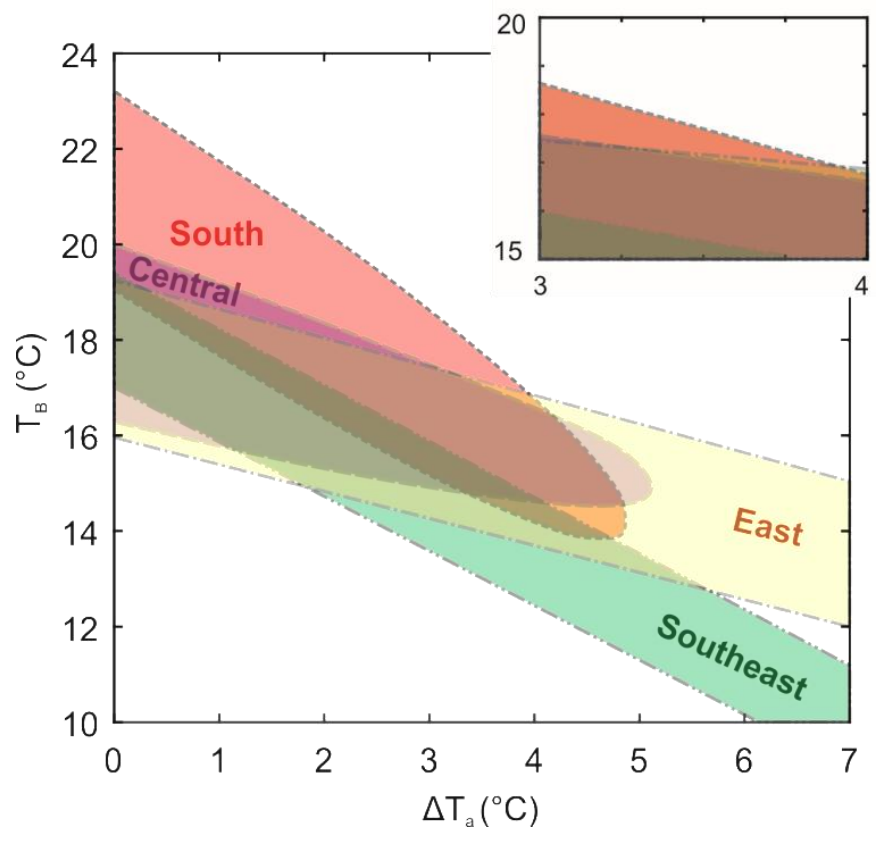

Figure 7. Ranges for inverted parameter values for the four borehole locations (RMSE $=0.3$ ${ }^{\circ} \mathrm{C}$ at the Central location and $\mathrm{RMSE}=0.1{ }^{\circ} \mathrm{C}$ at other sites) with full range (left) and closeup based on recommended range (right).
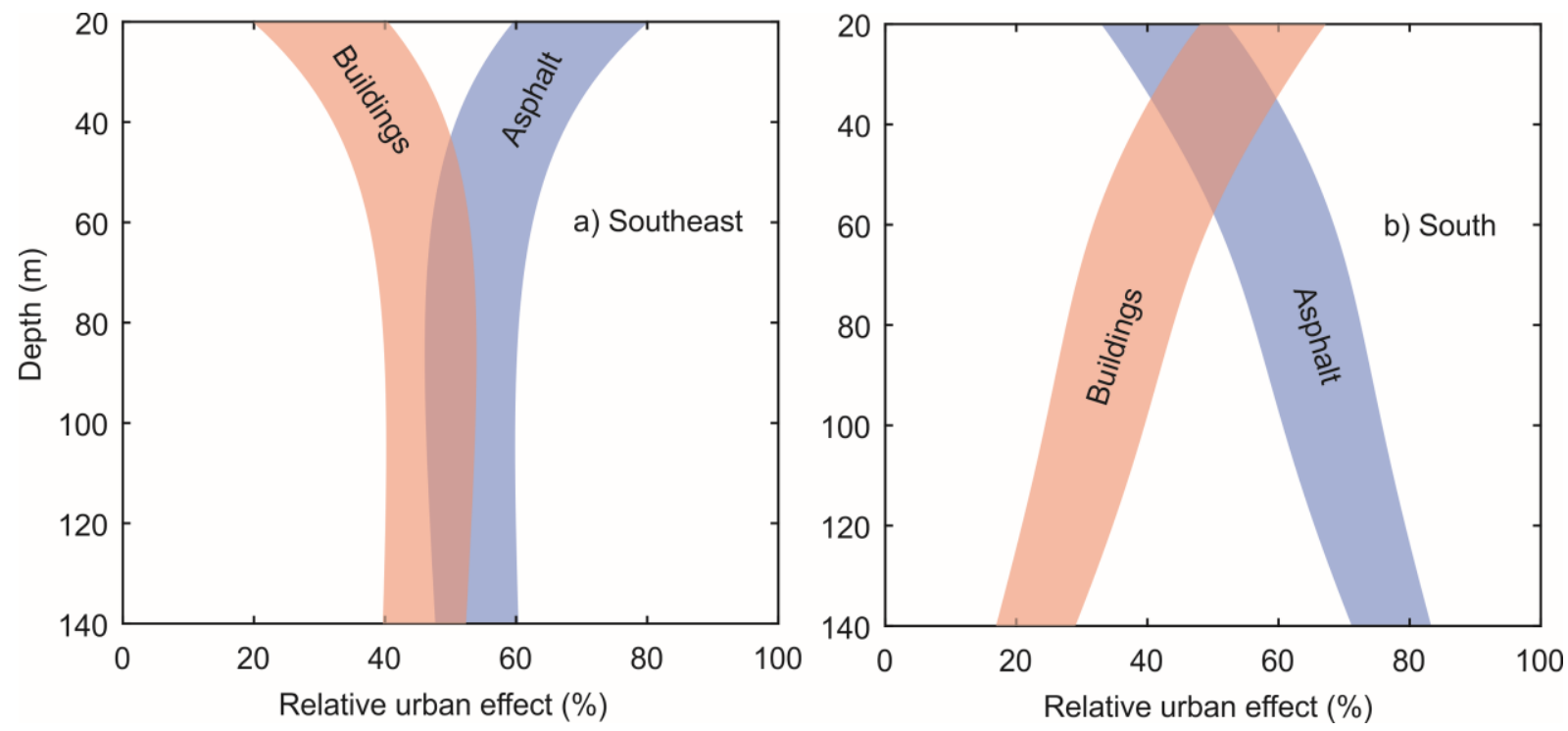

Figure 8. Depth-dependent contribution by buildings and asphalted ground at Southeast and West borehole, given the ranges derived from the inversion. 

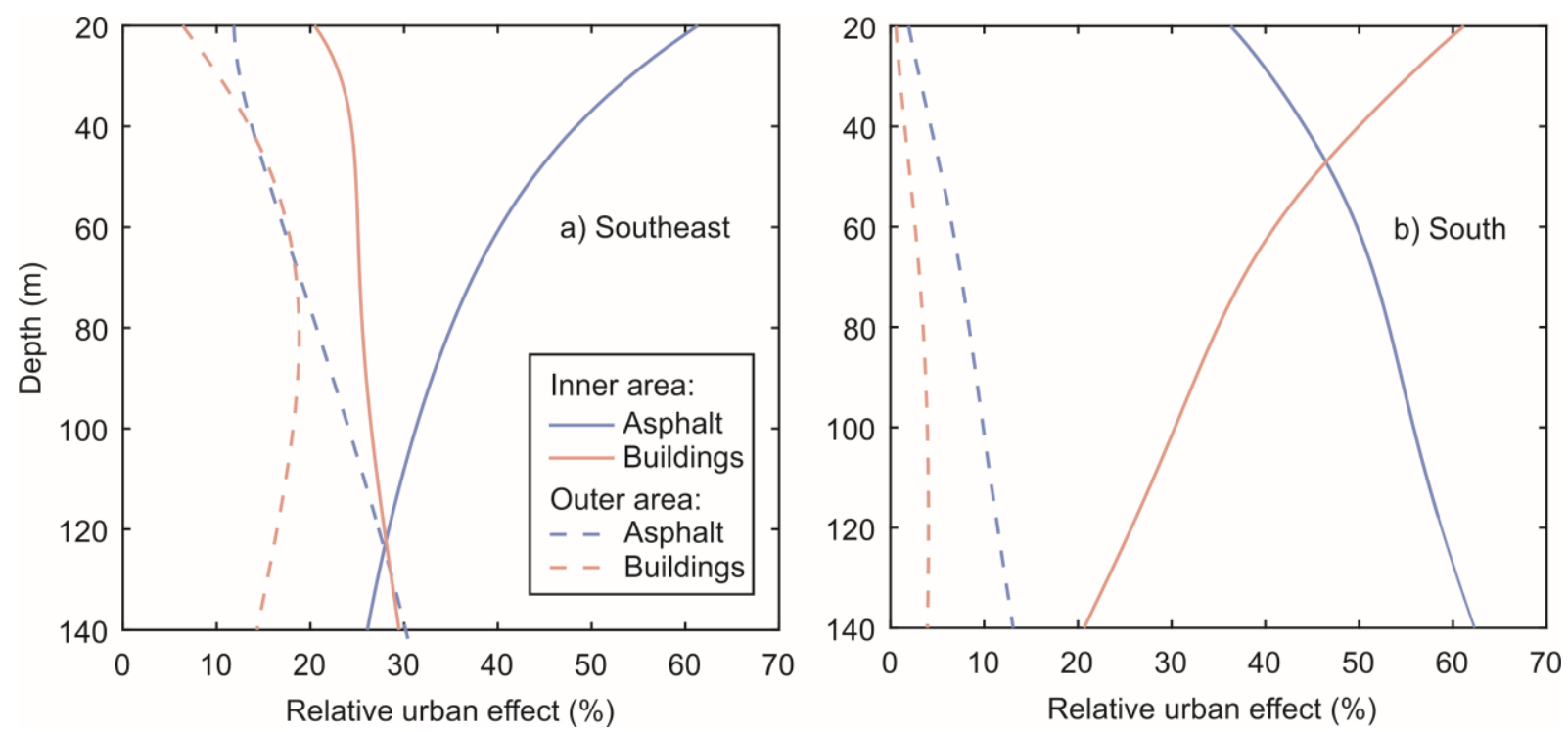

Figure 9. Depth-dependent contribution by inner and outer zones at South and Southeast location, as distinguished in Figure 5a, b.

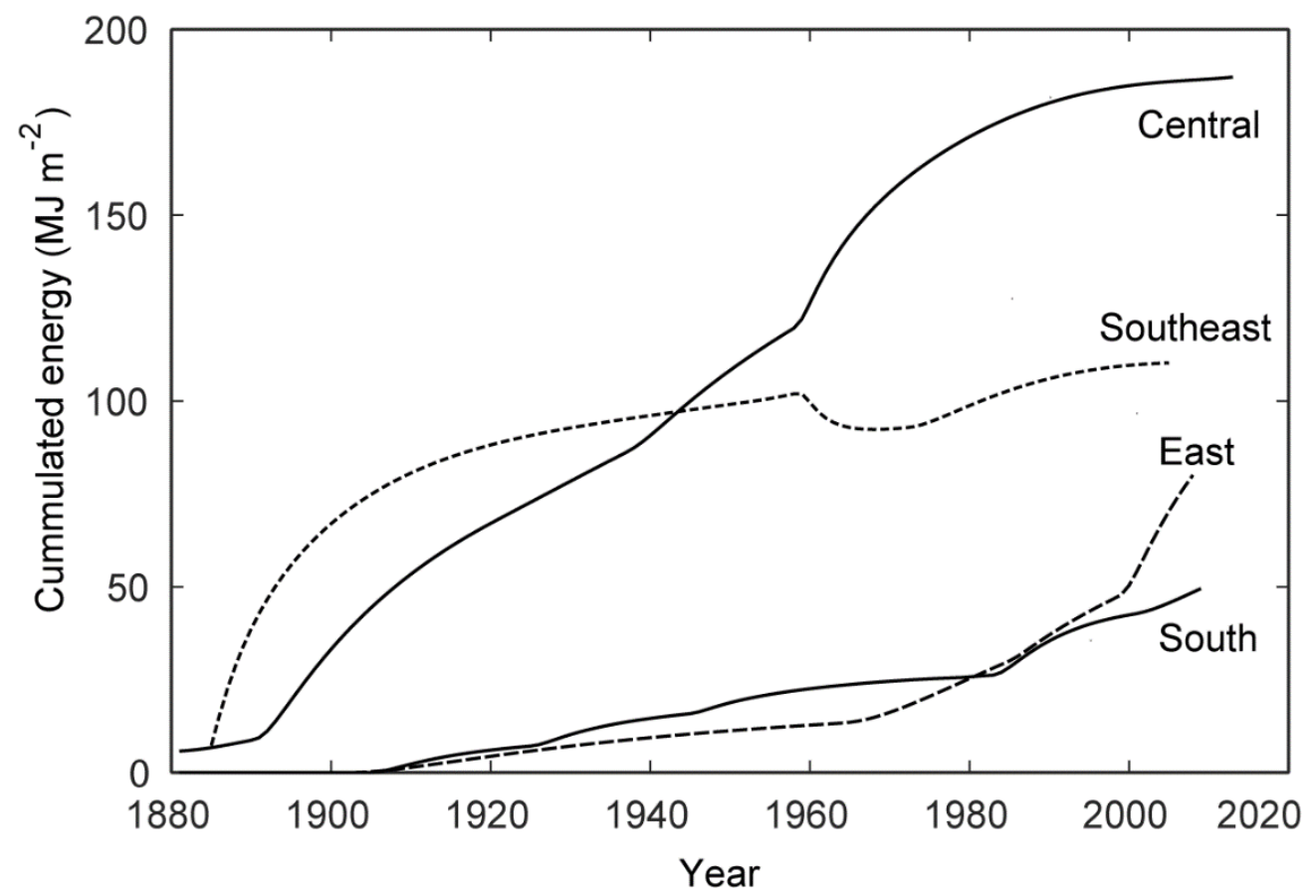

Figure 10. Evolution of cumulative subsurface heat gain from buildings and paved ground at the four case studies. 